\title{
A Histopathological spectrum of nephrectomy specimens in a tertiary hospital of Raipur city (C.G.) India
}

\author{
Thakur A.S. ${ }^{1}$, Gahine R. ${ }^{2}$, Banjare B. ${ }^{3}$ \\ ${ }^{1}$ Dr. Ajay Singh Thakur, Assistant Professor, ${ }^{2}$ Dr. Renuka Gahine, Director \& Professor, ${ }^{3}$ Dr. Bimla Banjare, Associate \\ Professor; all authors are attached with Department of Pathology, Pt JNM Medical College Raipur (CG) India.
}

Corresponding Author: Dr. Bimla Banjare, Associate Professor, Department of Pathology, Pt JNM Medical College, Raipur (CG) India. E-mail: dhiraj.bhawnani@gmail.com

\begin{abstract}
Introduction- Kidneys are one of the major organs of the human body that serve several essential functions. Their main function is to regulate the balance of electrolytes in the blood, along with maintaining $\mathrm{pH}$ homeostasis. Kidneys are affected by various non-neoplastic and neoplastic pathological processes. Kidneys with end stage renal disease can give rise to major complications such as massive bleeding for which nephrectomy may be indicated. Radical or partial nephrectomy is the treatment of choice for a great proportion of patients with renal tumors. Materials and Methods- This was a retrospective study carried out in the Department of Pathology in Pt. J. N. M. Medical College Raipur, Chhattisgarh, India. A total of 54 nephrectomy specimens received during the period were included in the study. Paraffin blocks and slides along with case records were retrieved and studied. Results- Patients with a male to female ratio of 1.3:1. Maximum cases of chronic pyelonephritis were seen in the age group of 31-40 years. Among 54 nephrectomy cases, 16(29.6\%) cases were non-neoplastic lesions and 38 (70.4\%) of the cases were neoplastic lesions. Among 20 cases of renal cell carcinoma, clear cell renal carcinoma 9 (45\%) cases was the most frequent followed by papillary RCC 7 (30\%) cases. Other tumors included $2(10 \%)$ cases of unclassified RCC, one (05\%) case each of chromophobe RCC, medullary RCC and collecting duct RCC. Conclusion- A wide histopathological range of lesions comprised of neoplastic and non-neoplastic lesions was found. Increase in availability of early diagnosis and appropriate better treatment facilities causes decrease in need of surgical treatment for inflammatory lesions of kidney.
\end{abstract}

Keywords- Histopathological spectrum, Nephrectomy, Xanthogranulomatous pyelonephritis,

\section{Introduction}

Kidneys are one of the major organs of the human body that serve several essential functions. Their main function is to regulate the balance of electrolytes in the blood, along with maintaining $\mathrm{pH}$ homeostasis. They also remove waste products of metabolism from blood and produce erythropoietin to maintain hematopoiesis and an important enzyme, renin to maintain blood pressure [1].

Kidneys are affected by various non-neoplastic and neoplastic pathological processes. Common clinical conditions involving the kidney include the nephritic and nephrotic syndromes, renal cysts, acute kidney injury, chronic kidney disease, urinary tract infection, nephrolithiasis, urinary tract obstruction and various cancers of the kidney [2]. Because of widespread use of imaging, increased number of renal lesions is being

Manuscript received: $8^{\text {th }}$ August 2019

Reviewed: $18^{\text {th }}$ August 2019

Author Corrected: $24^{\text {th }}$ August 2019

Accepted for Publication: $27^{\text {th }}$ August 2019 discovered. These renal conditions can be managed medically or surgically. Surgical removal of the kidney is known as nephrectomy. Nephrectomy is the standard surgical procedure performed in irreversible kidney damage and in the case of renal malignancies [1].

Nephrectomy is of many types; partial, simple and radical nephrectomy. Partial nephrectomy involves removing a small portion of the kidney. A simple nephrectomy performed for living donor transplant purposes requires removal of the kidney and a section of the attached ureter. Radical nephrectomy involves removing the entire kidney including adrenal gland and the fatty tissue surrounding the kidney [3].

Kidneys with end stage renal disease can give rise to major complications such as massive bleeding for which nephrectomy may be indicated. Other less frequent indications for nephrectomy intractable hypertension, pain, and repeated infections. Kidney removed for one of 
Original Research Article

the distinct but related conditions such as obstructive nephropathy, hydronephrosis, and chronic pyelonephritis is the most frequent type of nephrectomy specimen for nonneoplastic renal diseases in both adults and children.

Xanthogranulomatous pyelonephritis is also an indication for nephrectomy. Nephrectomy is the treatment modality in cystic renal dysplasia [4].

Renal tumours comprise a diverse spectrum of neoplastic lesions with patterns that are relatively distinct for children and adults. A wide variety of both benign and malignant tumours arise from different components of the renal parenchyma, notably tubular epithelium. Radical or partial nephrectomy is the treatment of choice for a great proportion of patients with renal tumors $[4,5]$.

Accurate diagnosis of most renal tumours is not possible before surgery and histopathological evaluation is essential. A detailed and meticulous histopathological examination of nephrectomy specimen is required to establish histological type and to record accepted histopathological prognostic determinants i.e. tumor size, histological subtype, nuclear grade and stage in cases of malignant renal neoplasms [6].

Histological subtype according to the Heidelberg classification5 of Renal cell carcinoma include clear cell ("conventional") adenocarcinoma (80\%), papillary $(15 \%)$, chromophobe $(5 \%)$, collecting duct $(1 \%)$, and unclassified (4\%).

Primary squamous cell carcinoma of the kidney is a very rare entity. The incidence of renal squamous cell carcinoma among renal tumor is in the range of $0.5-0.8 \%$ [7].

Wilm'stumor though ranked fifth in frequency among childhood solid tumours and it is the most common childhood abdominal malignancy. It is seen primarily in infants, $50 \%$ of the cases before the age of 3 years and $90 \%$ before the age of 6 years. Benign neoplasms are adenoma, oncocytoma \& metanephric adenoma and angiomyolipoma $[7,8,9]$.

\section{Materials and Methods}

Type of study- Retrospective study

Study setting- Department of Pathology in Pt. J. N. M. Medical College Raipur, Chhattisgarh, India.

Sampling methods \& Sample collection- Universal sampling method. A total of 54 nephrectomy specimens received during the period from January 2013 to September 2018 were included in the study.

Inclusion criteria- Nephrectomy Specimen of any age and sex having non neoplastic or neoplastic (benign and malignant) lesions that undergone histo-pathological examination following surgery was included in this study.

Exclusion criteria- The patients who underwent core needle biopsies from their renal masses were excluded.

Ethical approval: The study was approved by the Institutional Ethics Committee.

Procedure- Patient particulars were recorded in detail including investigations like USG \& CT scan findings. The cases were reviewed with respect to age, sex, pathological diagnosis, clinical presentation, laboratory investigations. All the nephrectomy specimens were fixed in $10 \%$ formalin, specimens were inspected, and gross findings, weight and dimensions were recorded. Grossing of formalin fixed specimen and processing of tissue was done according to standard protocol and bits were taken from representative areas.

The selected blocks were then processed through, ascending concentration of alcohol, cleared by xylene, embedded in paraffin and cut at 3-4 $\mu$ thickness. Sections from each block were stained conventionally by Haematoxilin and Eosin stain. Because of present study were a retrospective case, paraffin blocks and slides along with case records were retrieved and studied.

Statistical methods- Data was recorded in MS EXCEL and checked for its completeness and correctness then it was analysed by suitable statistical software.

\section{Results}

Maximum cases of chronic pyelonephritis were seen in the age group of 31-40 years. Majority of renal cell carcinoma seen in patients between 31-60 years of age group, while Wilms' tumor was mainly seen in patients below the age of 10 years.

Highest percentage of patients belonged to $0-10$ years age group with $33.3 \%$ (18cases), followed by those in the age group $31-40$ with $22.2 \%$ (12 cases). $57.4 \%$ were men \& $42.6 \%$ were women [Table-1].

Table-1: Age \& Sex wise distribution of nephrectomy cases. 


\begin{tabular}{|c|c|c|}
\hline Age distribution (years) & No. & Percentage (\%) \\
\hline 0 to 10 & 18 & 33.33 \\
\hline 11 to 20 & 1 & 1.85 \\
\hline 21 to 30 & 8 & 14.81 \\
\hline 31 to 40 & 12 & 22.22 \\
\hline 41 to 50 & 6 & 11.11 \\
\hline 51 to 60 & 7 & 12.96 \\
\hline 61 to 70 & 1 & 1.85 \\
\hline 71 to 80 & 1 & 1.85 \\
\hline Sex & 31 & $57.4 \%$ \\
\hline Male & 23 & $42.6 \%$ \\
\hline Female & \multicolumn{2}{|}{} \\
\hline
\end{tabular}

Table-2: Distribution of lesions in nephrectomy cases

\begin{tabular}{|c|c|c|}
\hline Lesion & No of cases $(\mathbf{n}=\mathbf{5 4})$ & Percentage $(\boldsymbol{\%})$ \\
\hline Non-neoplastic & 16 & 29.6 \\
\hline Neoplastic & 38 & 70.4 \\
\hline Total & $\mathbf{5 4}$ & $\mathbf{1 0 0}$ \\
\hline
\end{tabular}

Among 54 nephrectomy cases, 16(29.6\%) cases were non-neoplastic lesions and $38(70.4 \%)$ of the cases were neoplastic lesion [Table 2].

Table No.-3: Histopathological spectrum of nephrectomy cases

\begin{tabular}{|c|c|c|}
\hline Histopathological finding & Number & Percentage \\
\hline Non- neoplastic & 16 & 29.62 \\
\hline CPN with hydronephrosis & 7 & 13.0 \\
\hline $\mathrm{CPN}$ & 4 & 7.4 \\
\hline Abscess & 2 & 3.7 \\
\hline Hydronephrosis & 1 & 1.9 \\
\hline Xanthogranulomatous Pyelonephritis & 1 & 1.9 \\
\hline Polycystic kidney diseases & 1 & 1.9 \\
\hline Neoplastic & 38 & 70.4 \\
\hline \multicolumn{3}{|l|}{ Benign } \\
\hline Angiomyolipoma & 1 & 1.9 \\
\hline \multicolumn{3}{|l|}{ Malignant } \\
\hline Renal cell carcinoma & 20 & 37.0 \\
\hline Wilms tumor & 16 & 29.6 \\
\hline Squamous cell carcinoma & 01 & 1.9 \\
\hline
\end{tabular}

Out of 38 neoplastic lesions only one (2.6\%) case underwent nephrectomy for a benign renal tumor. The rest of the cases underwent nephrectomy for malignant tumors were 37 (97.4\%) cases.

Among the non-neoplastic lesions, chronic pyelonephritis with hydronephrosis 07 (13.4\%) cases was the most common inflammatory condition for which nephrectomy was done. It was followed by CPN 4 (7.4\%) cases; renal abscess $2(3.7 \%)$ cases and one (1.9\%) case each of hydronephrosis, xanthogranulomatous pyelonephritis and polycystic kidney disease. 


\section{Original Research Article}

Neoplastic diseases: Renal neoplasm's constituted 38 cases, malignant tumors 37 (97.4\%) cases were outnumbered compared to benign $1(2.6 \%)$ case. Angiomyolipoma 01(1.9) case was the benign tumor seen in the present study. Among the malignant tumor, renal cell carcinoma was commonest 20(37.0\%) cases; followed by wilms tumor $16(29.6 \%)$ cases. It was noted that single (1.9\%) case of squamous cell carcinoma of renal pelvis [Table-3].

Table-4: Histological variants of renal cell carcinoma.

\begin{tabular}{|c|c|c|}
\hline Histopathological variant & No. of cases & Percentage \\
\hline Clear cell & 09 & 45.0 \\
\hline Papillary & 06 & 30.0 \\
\hline Undifferentiated & 02 & 10.0 \\
\hline Medullary & 01 & 05 \\
\hline Chromophobe & 01 & 05 \\
\hline Collecting duct & 01 & 05 \\
\hline Total & $\mathbf{2 0}$ & $\mathbf{1 0 0}$ \\
\hline
\end{tabular}

Among 20 cases of renal cell carcinoma, clear cell renal carcinoma $9(45 \%)$ cases was the most frequent followed by papillary RCC $6(30 \%)$ cases. Other tumors included $2(10 \%)$ cases of unclassified RCC, one $(05 \%)$ case each of chromophobe RCC, medullary RCC and collecting duct RCC [Table-4].

\section{Discussion}

In the present study, out of 54 nephrectomy cases 16 (29.6\%) cases were non-neoplastic and 38(70.4\%) cases were neoplastic, similar higher incidence of neoplastic lesions of $52.9 \%$ and $58.46 \%$ were reported in other studies also. [10,11]. Number of nephrectomies done for non-neoplastic conditions has declined because of better antibiotic availability and minimally invasive techniques used these days for treatment of kidney stones. Also, patients are being treated at an earlier stage. However, a higher incidence of nonneoplastic lesions of $63.8 \%$ and $78.1 \%$ were reported in studies done by Chitra et al and $\mathrm{K}$. Ramakrishna et al respectively $[10,11,12,13]$.

Non-Neoplastic diseases- The non-neoplastic category included both inflammatory as well as congenital disorder. Out of 16 cases of non-neoplastic disorders, infective/inflammatory pathology formed a predominant subgroup comprised of 15 cases. Hence, there is a need to emphasize the importance of early diagnosis and proper treatment of urinary tract infections and nephrolithiasis.

Among the non-neoplastic lesions, Chronic pyelonephritis with hydronephrosis (07 cases) was the most common condition for which nephrectomy was done which was similar to study done by Vikram KS et al and Amin et al was, followed by CPN (04) cases) and renal abscess (02 cases), with one case each of hydronephrosis, Xanthogranulomatous pyelonephritis and polycystic diseases of childhood $[4,10]$. Pyelonephritis is seen in all age group. In the present study majority of pyelonephritis were seen between 4 th to 6th decade This was comparable to the study conducted by Aniff et al, Chaitra et al, Amin et al and Bharti et al $[4,12,14,15]$. It was observed slightly female predominance over male in cases of chronic pyelonephritis as a pure lesion and associated with hydronephrosis and Xanthogranulomatous pyelonephritis, similar to Abdulghafoor et al and Chitra et al [3, 12].

Globally the incidence of xanthogranulomatous pyelonephritis is 0.6 to $1 \%$ with female preponderance. It was encountered with only one case $(1.9 \%)$ in a $33-$ year-old female patient, this is similar to study done by Swarnalata Ajmera et al who have reported similar incidence. Savita D et al and Shaila et al also noted similar type of observation in their studies $[11,16,17]$.

Neoplastic diseases- Nephrectomy is a standard treatment offered to patients who present with benign as well as malignant mass lesions in the kidney. Most common malignant tumor in adults is renal cell carcinoma (RCC) and Wilms tumor in childhood. Rare are urothelial tumors of calyces and pelvis [12].

It affects older individuals usually in the 6th and 7th decades and show male preponderance (2 to 3:1). Most renal carcinomas are sporadic. Familial variants (4\%) consisting of Von Hippel-Lindau (VHL) Syndrome, Hereditary (familial) clear cell carcinoma and Hereditary papillary carcinoma [10]. In the present study, a total of 38 neoplastic lesions were reported. Maximum cases were malignant tumors (37 cases-97.4\%) as compared to benign cases ( 1 case-2.6\%), Renal cell carcinoma was the commonest malignancy with an incidence of $52.6 \%$. 


\section{Original Research Article}

Wilms tumor was second most common malignant lesion, it was observed a total of 16 cases $(42.1 \%)$ in the present study. This was similar to the findings of Aniff et al and Shaila et al who observed that the majority of malignant neoplasm of the kidney were renal cell carcinomas $[4,11]$.

Incidence of renal cell carcinoma was more in male gender 13 cases $(65 \%)$ than female gender $07(35 \%)$. Aniff et al, Nushrat et al, Amin et al and Savita et al also observed male predominance in their studies $[4,11,14$, 16].

Among the renal cell carcinomas it was observed that left sided involvement was more 14 cases $(70 \%)$ than right side 06 cases (30\%), concordance to that observed by Swarnlata Ajmera et al $-63.3 \%$ in left kidney and 36.7\% in right kidney, similar findings were also noted by Nushrat et al, Amin et al and Savita et al in their studies $[5,11,14,16]$.

Majority of the renal cell carcinomas were seen in $3^{\text {rd }}$ to $6^{\text {th }}$ decades of life. This observation is similar to the study done by Chitra et al [12].

In the present study commonest type of renal cell carcinoma was clear cell type accounting for 09 cases $(45 \%)$ followed by 6 cases $(30 \%)$ of papillary type. This is in accordance with many other studies like Shaila et al, Chitra et al and Bharti et al $[11,12,15]$.

It was observed 2 cases $(10 \%)$ of undifferentiated carcinoma in the present study and one each case of Medullary type, Chromophobe type and Collecting duct type RCC.

Similar type of observation is seen in the study done by Vikram Narang et al that studied 82 cases of RCC and observed 1 case each of Chromophobe RCC, collecting duct RCC [10].

Primary squamous cell carcinoma of the kidney is a very rare entity. The incidence of renal squamous cell carcinomas among malignant renal tumors is in the range of $0.5-0.8 \%$, as reported by Li et al. and Blacher et al. In the present study, it was noted only one case of squamous cell carcinoma was seen in a 47-year-old man. Similar type of observation is seen in the study done by Kotta et al and Aniff et al $[1,11]$.

In the present study, 16 cases (42.1\%) of Wilm's tumor were seen among all malignant renal tumors, which is concordance with the study done by Amin et al. The youngest patient was 6 months old and the oldest patient was 27 years of age. Majority of cases (13) were seen in pediatric age group (0-10-year age group) [14].

\section{Conclusion}

A wide histopathological range of lesions comprised of neoplastic and non-neoplastic lesions was found in the current study. Wilms tumor was the most common childhood tumor and in adults renal cell carcinoma was most common malignancy where aschronic pyelonephritis (CPN) with hydronephrosis was most common non-neoplastic lesion. The trend may indicate, in the present time increase in availability of early diagnosis and appropriate better treatment facilities causes decrease in need of surgical treatment for inflammatory lesions of kidney.

\section{What this study adds to existing knowledge?}

There is a scarcity of studies on this topic in the present study area. The present study gives an overview of the morphological patterns of lesions in nephrectomy specimens in middle India. So, the appropriate diagnostic and treatment modilities should be developed to address the same.

\section{Author's contribution}

Dr. Ajay Singh Thakur: Conception, Design, Supervision, Materials, Data collection/ processing, Analysis, Literature review, Writer, Critical Review.

Dr. Renuka Gahine: Design, Supervision, Materials, Data collection/processing, Analysis, Literature review, Writer, Critical Review.

Dr. Bimla Banjare: Design, Supervision, Materials, Data collection/processing, Analysis, Literature review, Writer.

Findings: Nil; Conflict of Interest: None initiated Permission from IRB: Yes

\section{References}

1. Reddy KD, Gollapalli SL, Sujitha C, Sidagam S, khan Mohmmed A, Bommana A. A Clinico-Morphological Spectrum of Nephrectomy Specimens-An Experience from a Tertiary Care Hospital.

2. Kumar V, Abbas AK, Fausto N, Aster JC. Robbins and Cotran pathologic basis of disease, professional edition e-book. Elsevier Health Sciences; 2014 Aug 27.

3. Abdulghafoor S. Abdulkareem, Bashar A. Hassawi, Ziyad Ahmed. Nephrectomy. A clinicopathological study. J Am Sci 2015;11(8):97-101. 


\section{Original Research Article}

4. Aiman A, Singh K, Yasir M. Histopathological spectrum of lesions in nephrectomy specimens: A fiveyear experience in a tertiary care hospital. J Sci Soc. 2013; 40(3):148.

5. Bashir N, Bashir Y, Shah P, Bhat N, Salim O, Samoon $\mathrm{N}$, et al. Histopathological study of renal tumors in resected Nephrectomy specimens-An experience from teritary care centre. Nat J Med Res. 2015; 5(1):25-29.

6. Naiding M, Goswami A, Singh S. Histopathological Study of Spectrum of Renal Tumours In A Tertiary Care Centre - A Five Years Retrospective Study. J Sci. 2017; 7(6): 240-244. doi: http://dx.doi.org/10. 21276/ jos. 2017.7.6.2

7. Mehra M, Pramod, Gupta N, Sharma L. Histopathological Patterns of Renal Tumours Seen in Nephrectomy Specimens: A Three-Year Experience at a Tertiary Care Hospital in Western Part of Rajasthan. Int J Med Res Prof. 2016, 2(2); 221-224.

8. Latif F, Mubarak M, Kazi JI. Histopathological characteristics of adult renal tumours: a preliminary report. J Pak Med Assoc. 2011;61(3):224-228.

9. Motzer RJ, Bancer NH, Nanus DM, Renal cell carcinoma. N Engl J Med. 1996;355(12):865-875. doi: 10.1056/NEJM199609193351207

10. Narang V, Garg B, Walia A, Sood N, Malhotra V. Histomorphological Spectrum of Nephrectomy Specimens- A Tertairy Care Centre Experience. Nat J Lab Med. 2016;5(2):51-54. doi: NJLM/2016/18261: 2112.
11. Ajmera S, Ajmera R. Histopathological spectrum of lesions in nephrectomies -a five-year study. Int J Health Sci Res. 2017;6(7):44-46.

12. Chaitra B, Prema LP, Tejeswini V, Haritha O, Anusha M. Histopathology of nephrectomy specimens: A ten year south Indian tertiary hospital-based study. J Diagn Pathol Oncol. 2018;4(3):232-236. doi: 10.18231/ 2581-3706.2018.0048

13. Reddy KR, Sridevi C, Spectrum of Diseases in Nephrectomy Specimens Saudi J. Pathol. Microbiol. 2018;3(7):191-195. doi: 10.21276/sjpm.2018.3.7.4

14. Amin AN, Pai P, Upadyaya K. A Histopathological spectrum of nephrectomy specimens in a tertiary hospital in southern India. Int J Biol Med Res. 2015; 6 (3): 51735178 .

15. Thaker BD, Singh K. A histopathological review of Nephrectomy specimens Received in a Tertiary care hospital-A retrospective study. J Med Sci Clin Res. 2017; 5 (6): 23807-23810. doi: https://dx.doi.org/ 10. 18535/ jmscr/v5i6.167

16. Savita D, Parthiban R. Abhishek A. Spectrum of renal lesions encountered in a rural setup over a period of five years. J Diagn Pathol Oncol. 2018;4(3):202-207. doi: 10.18231/2581-3706.2018.0042

17. Shaila, Nityananda B. S, Tamil Arasi. "Spectrum of Lesions in Nephrectomy Specimens in Tertiary Care Hospital”. J Evol Med Dental Sci. 2015;4(73):1271412726. doi: $10.14260 /$ jemds/2015/1832.

\section{How to cite this article?}

Thakur A.S, Gahine R, Banjare B. A Histopathological spectrum of nephrectomy specimens in a tertiary hospital of Raipur city (C.G.) India. Trop J Path Micro 2019;5(9):627-632.doi:10.17511/jopm.2019.i09.03. 